\title{
Cosmetic Lateral Canthal Lengthening with 2 Tarsal Bites Made in the Periosteum
}

\author{
Jin Bin Kim¹, Jong Chan Kim¹, \\ Hyung Joo Lee ${ }^{2}$, Seil Lee', \\ Sung Gyun Jung ${ }^{1}$, Chan Min Chung ${ }^{1}$ \\ ${ }^{1}$ Department of Plastic and \\ Reconstructive Surgery, National Medical \\ Center, Seoul; ${ }^{2}$ Lee Hyung Joo Aesthetic \\ Clinic, Daejeon, Korea
}

No potential conflict of interest relevant to this article was reported.

\begin{abstract}
Asian eyes may have a narrow palpebral fissure and an upward Mongolian slant that is sometimes perceived as an angry or unfavorable expression. Among the various methods of oculoplastic surgery, lateral canthoplasty can alter the structure of the eyes such that they appear much bigger, thereby conveying a more favorable expression. We performed a lateral canthoplasty in which the lower eyelid tarsus was fixed to the periosteum while the lateral canthus was moved downward and backward. Here, we describe the surgical procedure we used to perform this technique.
\end{abstract}

Keywords Blepharoplasty, Cosmetic techniques, Eyelids

\section{INTRODUCTION}

Most women consider large eyes to be beautiful and believe that they may leave a favorable impression on others. Oculoplastic surgery is increasingly being performed to help individuals achieve this kind of physical appearance, and lateral canthoplasty is a type of surgical procedure that horizontally expands the palpebral fissure. The location where the lower eyelid is attached to the lateral canthal area is important in determining the shape of the palpebral fissure, and this location can be changed by lateral canthal anchoring during a lateral canthoplasty.

Many East Asians have eyes that are horizontally short and have an upwardly slanted palpebral fissure (i.e., the Mongolian slant). Their eyes can be enlarged through appropriate canthotomy and lateral canthal anchoring, which may result in a softer look. By performing a lateral canthoplasty and 2 rounds of lateral canthal anchoring, in which the tarsal plate was firmly fixed to the periosteum through a tarsal bite, we were able to correct the Mongolian slant and widen the lateral scleral triangle.

Received: Mar 24, 2017 Revised: May 2, 2017 Accepted: May 3, 2017 Correspondence: Chan Min Chung Department of Plastic and Reconstructive Surgery, National Medical Center, 245 Eulji-ro, Jung-gu, Seoul 04564, Korea. E-mail: nmcps.doctor@gmail.com

Copyright @ 2017 The Korean Society for Aesthetic Plastic Surgery.

This is an Open Access article distributed under the terms of the Creative Commons Attribution Non-Commercial License (http://creativecommons.org/licenses/by-nc/4.0/) which permits unrestricted non-commercial use, distribution, and reproduction in any medium, provided the original work is properly cited. $\quad$ www.e-aaps.org

\section{CASE}

\section{Patients}

From December 2011 to September 2016, 104 patients underwent lateral canthoplasty. The follow-up period ranged from 4 months to 4 years, with an average follow-up period of 16 months.

\section{Procedure}

We first drew an incision line from the lateral canthal area toward the lateral orbital rim along the upper eyelid margin. The end point of the incision line was designed not to cross the lateral orbital rim. The incision path was generally between 5 and $8 \mathrm{~mm}$ long and varied in length and direction depending upon the distance from the lateral canthus to the lateral orbital rim, the degree of the lower eyelid slant, patient expectations, and the opinion of the surgeon (Fig. 1).

The procedure was performed under local anesthesia (via local infiltration) and eye surface anesthesia using eye drops. First, $0.5 \%$ proparacaine hydrochloride eye drops (Alcaine; Alcon-Couvreur, Puurs, Belgium) were applied. Then, local infiltration with epinephrine $(1: 100,000)$ mixed with $2 \%$ lidocaine hydrochloride solution was performed using a 30-gauge needle.

After anesthesia, an incision was made from A to B, as shown in Fig. 1A, and dissection of the subcutaneous plane was performed. At this time, the lateral palpebral raphe of the lateral canthal area and a superficial portion of the lateral canthal tendon $[1,2]$ were released to sufficiently expose the canthal area and to allow easy rotation of the lower eyelid. If the rotation was not sufficient, a backcut was added to the palpebral conjunctiva. 

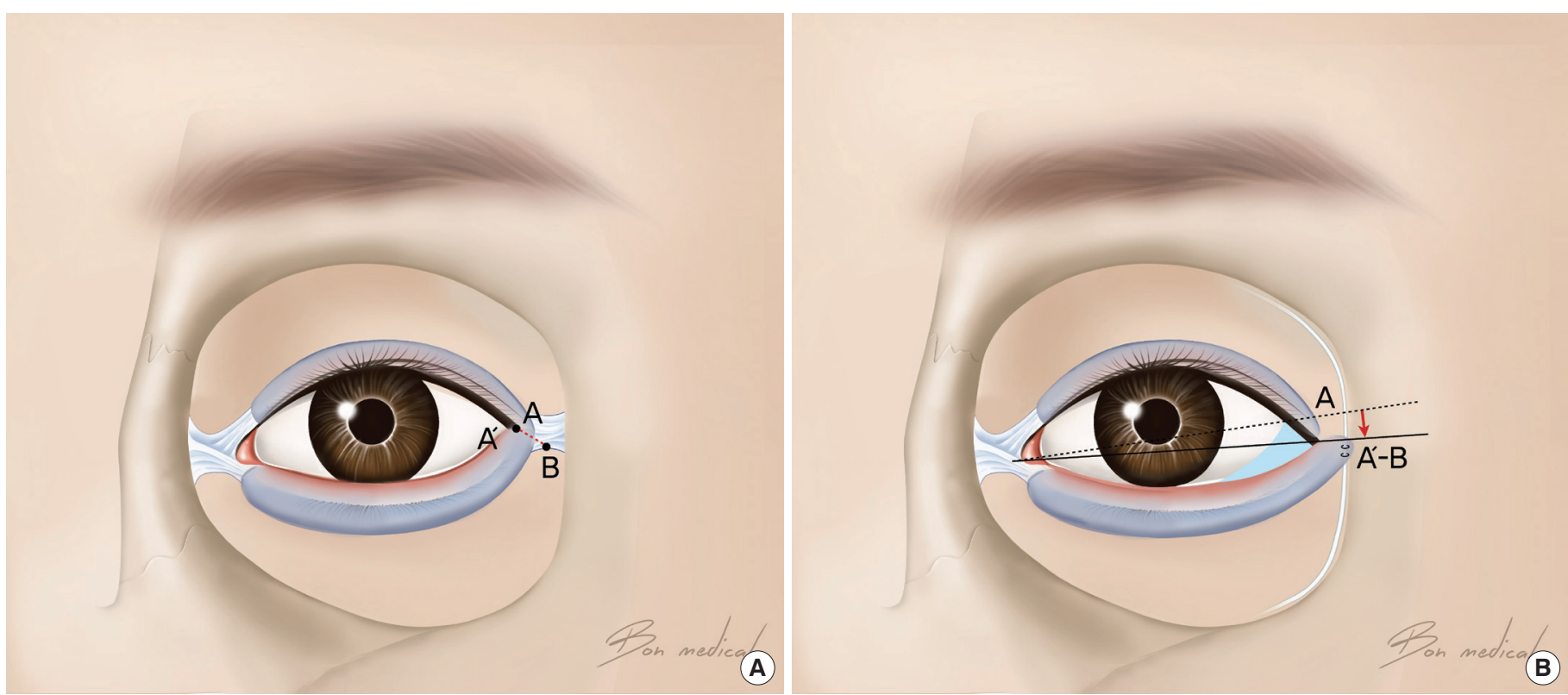

Fig. 1. (A) Schematic illustration of lateral canthoplasty. After anesthesia, an incision is made from $A$ to $B$. $A A^{\prime}$ : lateral canthus; $A B$ : incision line. (B) Two points of the tarsal bites to the periosteum were made with 5-0 nylon. A'-B: newly formed lateral canthus; shaded area: expanded portion after canthoplasty.

Next, we performed a key suture in which the lower eyelid was fixed to the periosteum of the lateral orbital rim. During this process, a 5-0 nylon suture was first passed through the periosteum, then through parts of the orbicularis oculi muscle, the tarsal plate, and, finally, the conjunctiva. While suturing, we moved from the inside of the periosteum to the inside of the orbital rim in order to maintain the vectors of the forces fixing the normal structures of the posterior lamella and to prevent eversion of the lower eyelid. To secure fixation, the anchoring suture was firmly fixed to the Whitnall tubercle and the surrounding area into which the deep portion of the lateral canthal tendon was inserted. In cases where the stump at which the lateral canthal tendon that was attached to the orbital rim was 6 to $7 \mathrm{~mm}$ wide [3], we started the bite from this location and ensured that it was firmly fixed. The skin suture was performed using 6-0 black silk suture.

\section{Postoperative care}

After surgery, oral antibiotics, ophthalmic solution, and artificial tears were prescribed. Steroid-containing eye drops were used only for a short period of time when the palpebral conjunctiva was swollen.

Sutures were removed between postoperative days 5 and 7. For 1 month following suture removal, patients were advised to avoid rubbing the surgical site and instructed to take only light showers.

\section{DISCUSSION}

Some Asians have horizontally small eyes with the Mongolian slant. This may be perceived as an angry expression. While the normal shape of the palpebral fissure and the location of the lateral canthal angle vary, a lateral canthal angle that is on the same line as the inferior edge of the pupil is generally accepted as ideal [4]. To achieve this look, corrective procedures, such as double eyelid surgery, medial epicanthoplasty, and lateral canthoplasty are increasingly being performed.

Certain principles must be considered and followed in order to minimize the occurrence of complications and to obtain the best results following lateral canthoplasty.

According to Shin and Hwang [5], the principles and guidelines for cosmetic lateral canthoplasty are as follows:

1. The continuity of the lower eyelid margin should be preserved.

2. The surface between the bulbar conjunctiva and the palpebral conjunctiva should remain in contact.

3. The patient's orbital condition should be more than $4 \mathrm{~mm}$ from the orbital rim to the lateral canthal angle in exophthalmometry.

During the surgical procedure performed in this study, an incision was made along the line that extended from the upper eyelid margin in order to preserve the continuity of the lower eyelid margin [6]. This incision did not cross the lateral orbital rim. Once the incision was made, structures around the lateral canthal area were dissected, and the lower eyelid was fixed to the periosteum.

Although the shape of an eyeball can affect the shape of the eyelid (which subsequently affects the shape of the eye fissure and scleral triangle), the tone and location of the canthal attachment affect the lid contour much more in the case of the lower eyelid. It is insufficient to perform only a skin suture after canthotomy. Therefore, satisfactory results can be obtained by changing the location 

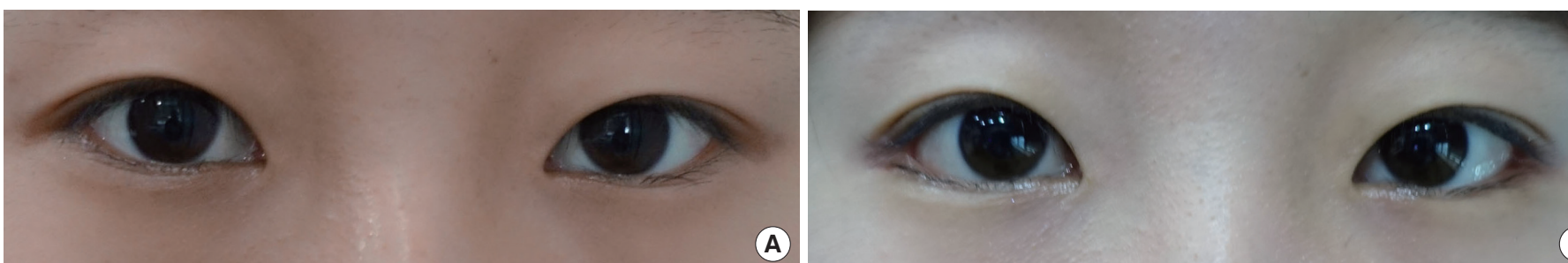

(A)
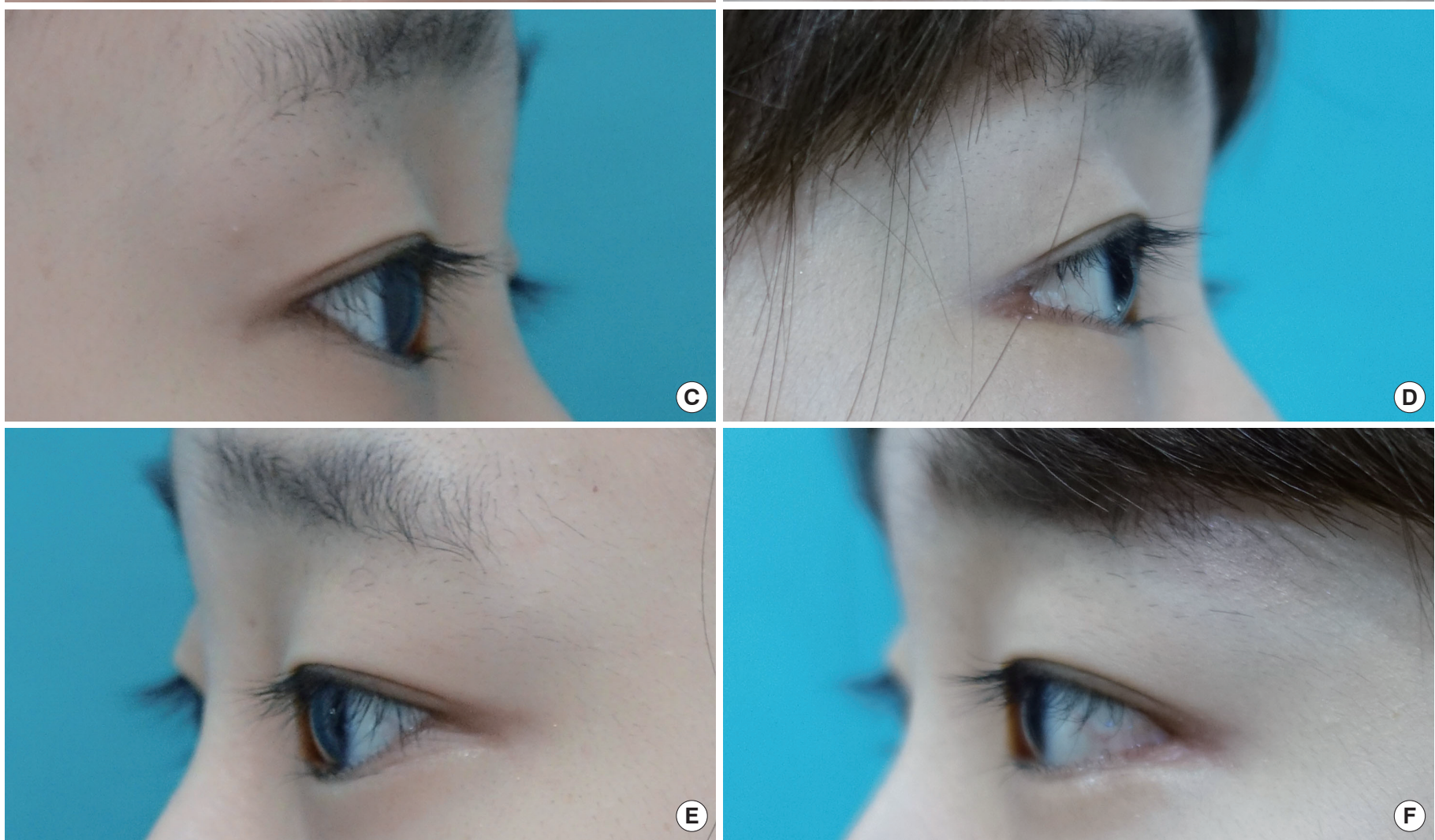

Fig. 2. Photographs of a 19-year-old female patient. Lateral canthoplasty was performed. (A, C, E) Preoperative photographs. (B, D, F) Photographs taken 3 months postoperatively.

of the lateral canthal anchoring when performing canthoplasty.

During our procedure, the authors considered the following in determining the fixation method and position:

1. Since the eye globe is round, it is important that the canthoplasty be done in both the lateral and posterior directions, rather than in only the lateral direction, to maintain contact between the bulbar conjunctiva and palpebral conjunctiva after lengthening the lateral canthus.

2. The lower tarsal plate has a dense fiber structure that is halfmoon shaped. It maintains the shape of the lower eyelid and connects the capsulopalpebral fascia and the lateral canthal tendon to the margin [7]. Therefore, it is necessary to maintain the anatomic connection of this structure after canthopexy.

3. Fixation should be done inside the lateral orbital rim to maintain the vector of the normal posterior lamella of the lower eyelid and to prevent eversion and conjunctiva exposure of the lower eyelid. This also should be done to prevent scarring that may occur due to excessive tension.

4. The purpose of this surgery is to provide patients who have a Mongolian slant with larger and brighter looking eyes. In order to achieve this goal, the Mongolian slant should be lowered.

5. Variations in periorbital anatomy among patients must be considered. For instance, assuming the mean protrusion of an eyeball measured through exophthalmometry is between 15 and $17 \mathrm{~mm}$, excessive anchoring in the downward direction can lead to scleral show in patients whose protrusions are more than the mean value. On the contrary, surgery will be more effective if more anchoring is performed in a downward and inward direction.

After considering each patient's need for eye size and shape, the surgeon chose the location of fixation on the inner surface of the orbital rim [8]. For secure fixation, we performed 2 rounds of lat- 

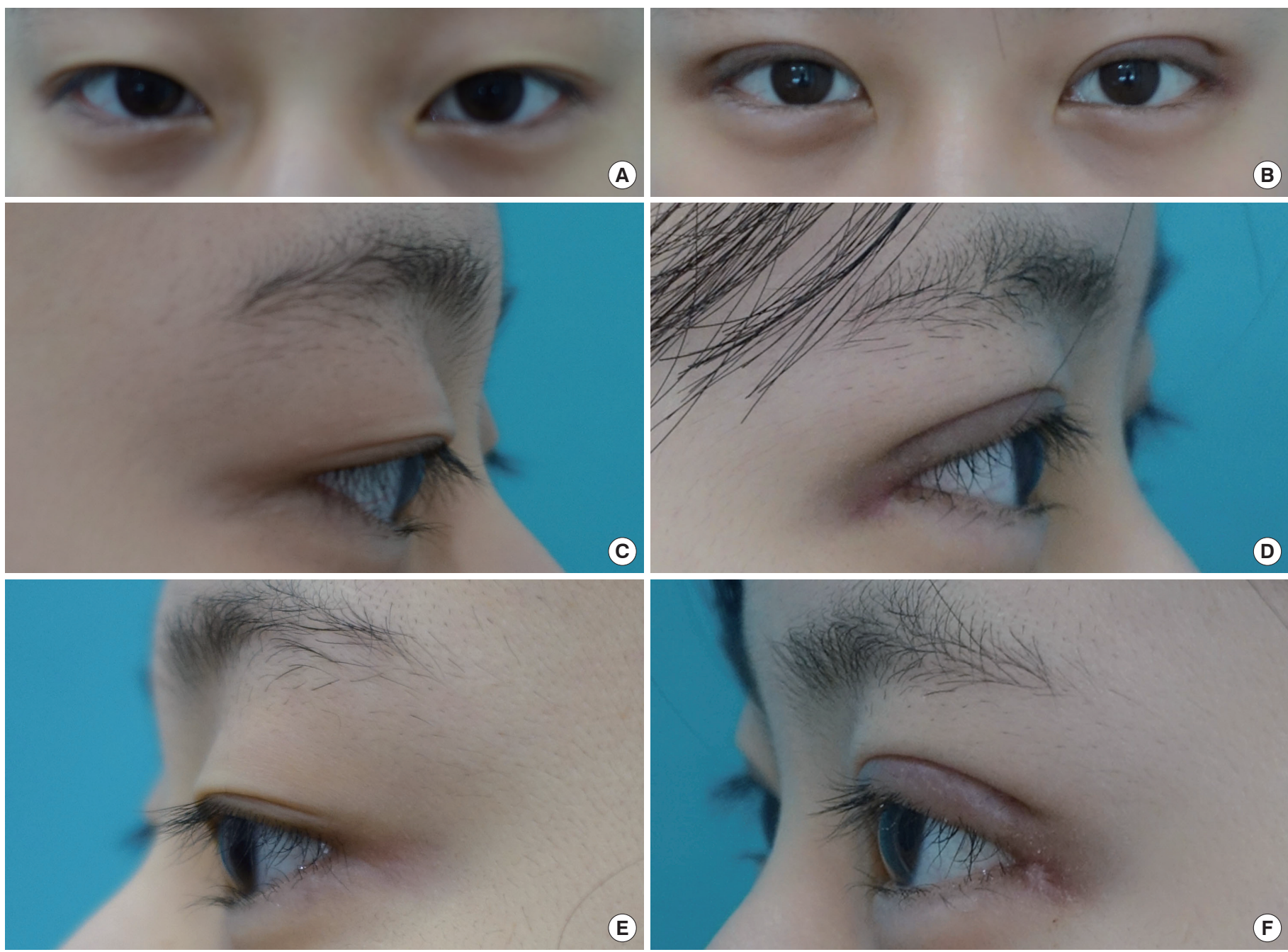

Fig. 3. Preoperative and postoperative photographs of a 17-year-old female patient. Non-incisional double eyelidplasty and lateral canthoplasty were performed. (A, C, E) Preoperative photographs. (B, D, F) Photographs 1 month postoperatively.

eral canthal anchoring with tarsal bites as a key suture; these sutures connected the periosteum of the lateral orbital rim, parts of the orbicularis oculi muscle, the tarsal plate, and the conjunctiva with only 1 pass-through. Following this key suture, canthoplasty was performed in the downward and posterior directions.

By stitching the tarsal plate while performing fixation on the periosteum, the amount of raw surface exposed was reduced. Secure fixation reduces tension at the suture site and prevents scarring. For this reason, we used a fixation suture on the periosteum of either the Whitnall tubercule or the stump of the deep portion of the lateral canthal tendon [9].

Some corneal edema and bleeding occurred after surgery. However, most patients recovered with conservative treatment. No patients experienced scar formation, such as hypertrophic scarring, keloid scarring, or webbing. The authors believe that both the 2 tarsal bites and the tension-free skin closure were important factors in preventing scar formation.
This method of surgery is adaptable to most patients. It was particularly successful when the distance from the lateral canthus to the lateral orbital rim was more than $4 \mathrm{~mm}$ and when the Mongolian slant was severe. These conditions resulted in the greatest patient satisfaction (Fig. 2 and 3).

This method is suitable for creating large and bright eyes in the appropriate patient population.

\section{PATIENT CONSENT}

Patients provided written consent for the use of their images.

\section{REFERENCES}

1. Kang H, Takahashi Y, Ichinose A, et al. Lateral canthal anatomy: a review. Orbit 2012;31:279-85.

2. Muzaffar AR, Mendelson BC, Adams WP, Jr. Surgical anatomy of the 
ligamentous attachments of the lower lid and lateral canthus. Plast Reconstr Surg 2002;110:873-84.

3. Dutton JJ. Atlas of clinical and surgical orbital anatomy. Philadelphia, PA: W.B. Saunders; 1994.

4. McCord CD, Boswell CB, Hester TR. Lateral canthal anchoring. Plast Reconstr Surg 2003;112:222-37.

5. Shin YH, Hwang K. Cosmetic lateral canthoplasty. Aesthetic Plast Surg 2004;28:317-20.

6. Hwang K, Nam YS, Kim DJ, et al. Anatomic study of the lateral palpe- bral raphe and lateral palpebral ligament. Ann Plast Surg 2009;62:232-6. 7. Kakizaki H, Zako M, Nakano T, et al. Microscopic findings of lateral tarsal fixation in Asians. Ophthal Plast Reconstr Surg 2008;24:131-5.

8. Hwang K, Kim HJ, Han SH, et al. Where to fix in rejuvenation surgeries?: tensile strength of the periosteum. J Craniofac Surg 2015;26:24850.

9. Anderson RL, Gordy DD. The tarsal strip procedure. Arch Ophthalmol 1979;97:2192-6. 